\title{
Modeling of Alternating Current Motor Performance for Increased Production Using Fuzzy Logic Controller
}

\author{
Ngang Bassey Ngang, Bakare Kazeem, Ugwu Kevin Ikechukwu, Aneke Nnamere Ezekiel \\ Department of Electrical and Electronic Engineering, Faculty of Engineering, Enugu State University of Science and Technology, Enugu, \\ Nigeria
}

Email address:

nbngang@gmail.com (N. B. Ngang)

\section{To cite this article:}

Ngang Bassey Ngang, Bakare Kazeem, Ugwu Kevin Ikechukwu, Aneke Nnamere Ezekiel. Modeling of Alternating Current Motor Performance for Increased Production Using Fuzzy Logic Controller. International Journal of Electrical Components and Energy Conversion. Vol. 7, No. 1, 2021, pp. 17-22. doi: 10.11648/j.ijecec.20210701.13

Received: May 3, 2021; Accepted: May 26, 2021; Published: June 9, 2021

\begin{abstract}
The low productivity experienced in our industries is as a result of not imbibing intelligence in its production mechanism. We know that induction motors are reliable, robust and with good operating characteristics. A means of starting, regulating and controlling operating parameters are very necessary to improve motor efficiency. This low productivity witnessed in our brewery industry is surmounted by modeling of alternating current (a.c) motor performance for increased production output using fuzzy logic controller. To achieve this it is done in this manner, characterizing and modeling a conventional AC motor so as to establish its operational features while working on variable frequency drive (VFD) control model with known production output, designing a rule base for the use of fuzzy controller for a stable and improved production output of AC motor and designing SIMULINK model for the performance of AC motor under operational condition for an increased output using fuzzy controller for a brewery industry. The results obtained are the highest conventional quantity of bottles of beer produced was 3240 while that of fuzzy controller was 3245 at a stable time of 4 through 10 seconds. With these results obtained, it shows there is an improvement in the production capacity in brewery industry when fuzzy controller is incorporated in the system.
\end{abstract}

Keywords: Modeling, Alternating Current, Motor, Increase Production, Fuzzy Controller

\section{Introduction}

From the field engineer's point of view, the concern about an alternating current machine is the way the terminal voltage varies with changes of load, and, with changes of the power factor. When current is being supplied by a synchronous generator, there will be a voltage 'drop' in the machine due to its impedance. Adjustable speed AC Motor drives these days, are used in the industry for many applications, hence, electrical and mechanical energy conversion using power electronics concept has given rise to increased output; Rotating electrical machines are electromechanical energy converters with a fundamental impact on the production and conversion of energy [1].

It is important to explain the concepts in the subject matter in order to better elucidate them as the work progresses. [2] Alternating Current (AC) Motors are electromechanical devices, driven by an alternating current (AC) and used to convert electrical power, in the form of alternating voltage and current, into mechanical energy. Currently, improving the energy efficiency of electric machines is a subject of high interest. Indeed electrical machines are widely used in industries, transportation and home applications.

Artificial Intelligence was defined as the ability of a digital computer or a computer-controlled robot to perform tasks commonly associated with intelligent beings [3]. The author's point of view is that the term applied to the project of developing systems which are endowed with the intellectual processes characteristic of humans, such as such as the ability to reason, discover meaning, generalize or learn from past experience. Similarly, in engineering, modeling is the process of creating a concept, hypothesis, design and testing in realworld conditions by making use of certain tools The induction motor is the most used motor type in the industrial and domestic applications. These types of motors are widely used due to its simple and robust construction, reliability and has self-starting capability. Induction motors are also called asynchronous motor because the mechanical speed they offer 
is different from their electrical speed. Three phase induction motor is a single excitation motor whose stator winding is supplied from three phase source. The rotor of an induction motor gains its energy by means of induction from the stator. The three-phase voltage creates a rotating magnetic field in the air gap. This rotating field interacts with the windings of the rotor inducing voltage and current in it. The rotating field rotates at a constant speed of synchronization [4]. To design an induction motor based on the equations, it is a bit complex, because equation whose terms are not of the first degree and more over when it is a strongly coupled system [5]. Furthermore, Modelling and Simulation $(M \& S)$ is the engineering use of developed models such as physical, mathematical or logical representations of both the static and dynamic states of an entity, system, process or phenomenon as a base for simulations aimed at developing utilized data for further technical or managerial decision making. [6], a critical factor in industrial production maintenance has to do with decision making in fault diagnosis. Motor current signature analysis (MCSA) is a condition based maintenance approach or method to make fault diagnosis in induction motors. Subsequent sections will elaborate the foregoing definitions. An induction motor is identical to a rotating transformer whose magnetic circuit is separated by an air gap [7]. The stator is considered as primary and rotor is taken as secondary winding and the Air gap between the two is considered as the core of the transformer [8]. For high dynamic performance, one must be able to control torque instantaneously. In the case of the induction motor, the torque comes from a coupling between flux and current. Many tools are now in use to for improving the performance of the power electronics in the industry to enhanced increased productivity. Some of these are, artificial intelligence, fuzzy logic, neural networks, hybrid networks, etc. They have been recently recognized as the important tools to improve output performance of machines in the industrial sectors. Utilization of these intelligent control with the adaptiveness seems to yield a promising research area in the development, implementation, and control of electrical drives.

The development and implementation of industrial control systems usually relies on mathematical models of the system components like, induction motors, synchronous generators, DC motors, and servo motors/controllers. In some cases, one could encounter problems for which a controller design becomes very complex and difficult to realize. When that happens, experienced field personnel are usually asked to apply the knowledge gained over the years. Human experts or experienced Technicians of the plants or systems would discover rules governing their actions for automatic control [9]. In this research, the fuzzy logic concepts together with artificial neural networks will be useful in developing the controllers for the plant. Alternating Current motors are widely used in the Oil and Gas industries especially in the field of electric drives \& control. Improper control of the speed of a motor couls result to malfunction of the system. It is always important to achieve a desired task for a specific application. AC motors, of the type, the squirrel-cage induction motors (SCIM), have many advantages like simplicity, reliability, low cost and, robustness and maintenance-free electrical drives. With all these characteristics inherent in the induction motors, for high dynamic performance industrial applications, their control usually becomes problematic due to their nonnonlinearities. The parameters of the rotating member that is the rotor resistance, vary with the operating conditions [10]. The dynamic or field orientation control (FOC) or vector control [11] of an alternating current machine that is inductive in nature achieves decoupled torque and flux dynamics leading to independent control of the torque and flux. Although the alternating current motor remains almost constant except on full load. The field engineer usually think in terms of speed instead of slip. The normal full load torque is always 5\% less than synchronous speed, and this gives a motor which is efficient to deliver at rated speed. If a high starting torque is required, that is on full load, the rotor will be made with highresistance conductors which will produce maximum torque at lower speed hence the need to use a an appropriate software tool to improve performance without affecting machine constants. [12]. Conventional means of using Proportional Integral Derivative (PID) controller deteriorates in performance with time. Now, the demand from the end-users in the field to use artificial intelligent control tools with classical control techniques have increased [13].

Many researched works were advanced and contributed to the design of such hybrid control schemes which was presented by various researchers in [14, 15]. Classical control monitoring systems such as PI, PID control had been used, alongside with vector control methods, to realize the speed control of alternating current induction machines by various researchers [16]. The main set back or drawbacks of the linear control techniques were the non-linearity and sensitivity in performance to the system parameters. To reduce the large starting current associated with induction motors, the voltage applied to the stator may be reduced [17]. Induction motors are applied widely various industries as prime movers to drive fans, pump water and Crude oil. The usual practice or Conventional control makes use of the mathematical model for the controlling of the system. Variations system parameters when on full load or during starting, or environmental disturbance (say noise), the behavior of system could be unsatisfactory change from the desired output performance [17].

\section{Methodology}

\subsection{Characterization and Modeling of a Conventional AC Motor}

The methodology has to do with the collection of data from a given motor under study. A typical 3-Phase Induction Motor was characterized and the result is shown as tabulated in Table 1. Additionally, other data collected from Ama brewery are also tabulated in Table 2 . The next step is to use the tabulated data to model the alternating Current motor using Fuzzy Logic Controller. A useful step to design a rule base for the use of Fuzzy Controller for a stable and improved production output. Proceed to design a SIMULINK Model for the performance of the alternating current motor 
under operational condition. A comparative analysis study would be done in terms of production output from the

conventional mode and Fuzzy-based method.

Table 1. Typical Parametric Values for a 3-Phase Induction Motor.

\begin{tabular}{lll}
\hline Symbol & Input Quantities & Values \\
\hline Power & Kilowatts \\
RPM & Speed (revolution per min) \\
$\varnothing$ & Phase & 2.19324 \\
$\mathrm{~F}$ & Frequency & 1500 \\
$\mathrm{P}$ & Poles & 3 \\
$\mathrm{VL}-\mathrm{L}$ & Line to Line Voltage & $50 \mathrm{~Hz}$ \\
$\mathrm{R}_{\mathrm{a}}$ & Armature resistance \\
$\mathrm{R}_{\mathrm{r}}$ & Rotor Resistance \\
$\mathrm{X}_{\mathrm{s}}$ & Stator Magnetizing Leakage Inductance \\
$\mathrm{X}_{\mathrm{r}}$ & Rotor Magnetizing Leakage Inductance \\
$\mathrm{X}_{\mathrm{m}}=\mathrm{L}$ & Mutual Inductance \\
$\mathrm{J}$ & Equivalent moment of inertia reflected \\
$\mathrm{B}$ & Equivalent viscous coefficient reflected at the motor shaft \\
$\mathrm{K} 1$ & Constant & $230 \mathrm{~V}$ \\
$\mathrm{~K} 2$ & Constant & $0.45 \Omega$ \\
$\mathrm{Te}$ & Electrical Torque (NM) \\
$\mathrm{T}_{\mathrm{L}}$ & Load torque & $3.2 \mathrm{mH}$ \\
\hline
\end{tabular}

Table 2. Collected parametric data from AMA brewery.

\begin{tabular}{llll}
\hline Voltage (V) & Speed REV/PM & Number of Crates Produced & Number of Bottles Produced \\
\hline 230 & 1500 & 270 & 3240 \\
\hline
\end{tabular}

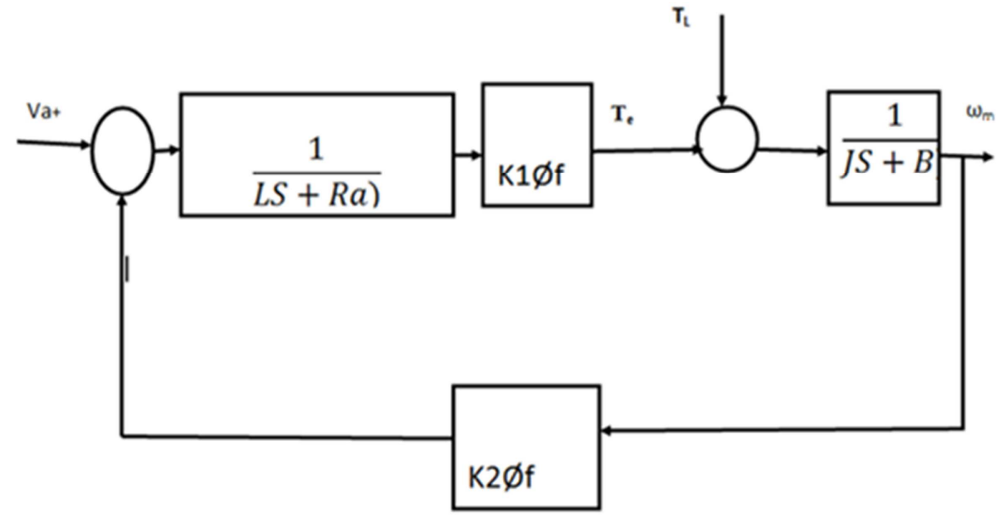

Figure 1. Block diagram of an AC motor.

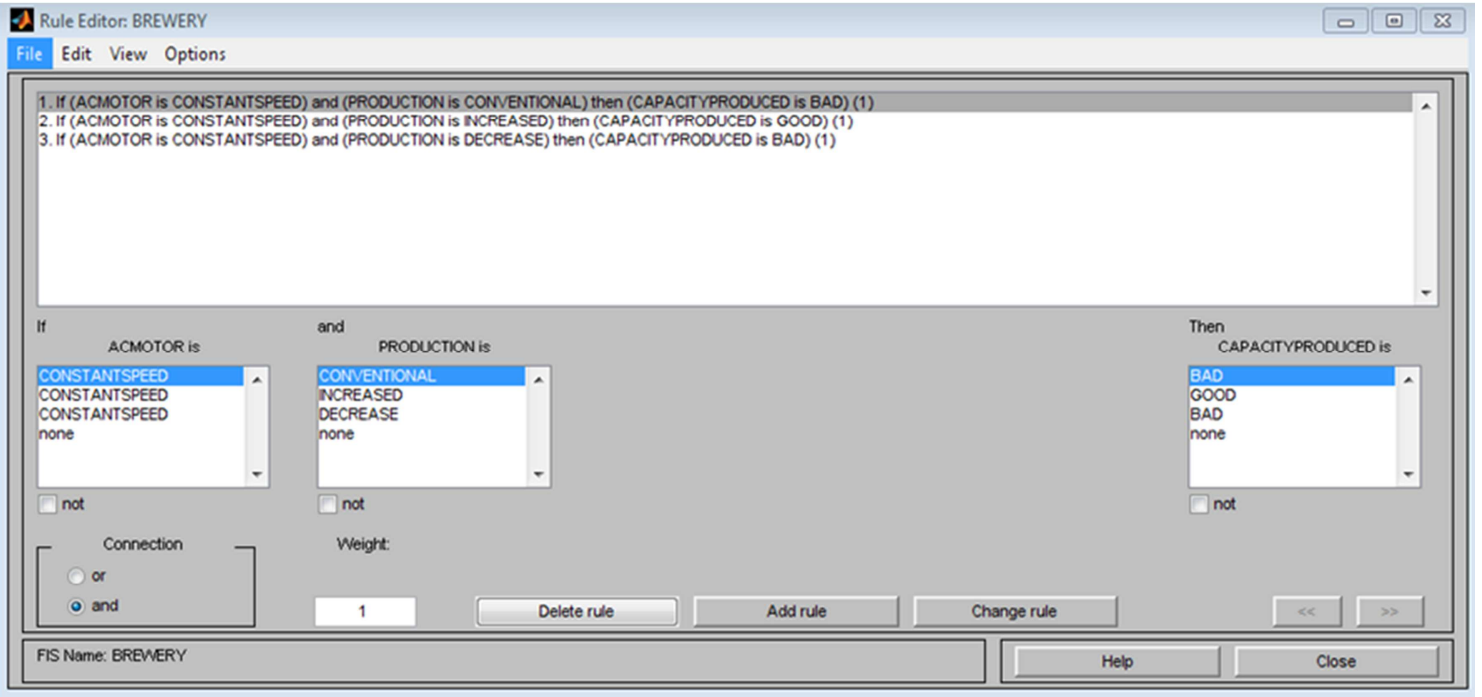

Figure 2. Fuzzy controller Rule Base for AC motor stable and improved production output. 


\subsection{To Design a Rule Base for the Use of Fuzzy Controller for a Stable and Improved Production Output of AC Motor}

The rule base module generated and shown in Figure 2 comprises a set of IF... THEN rules meant to guide the production principles and sequence using the AC induction motor as modeled using fuzzy controller. Table 3 shows a tabulated outline of this rule base.

Table 3. Developed production output rule base.

\begin{tabular}{llll}
\hline 1 & If ac motor is constant speed & and production output is conventional & then production capacity is bad. \\
2 & If ac motor is constant speed & and production output is increased & then production capacity is good \\
3 & If ac motor is constant speed & and production output is decreased & then production capacity is bad \\
\hline
\end{tabular}

\subsection{SIMULINK Model for the Performance of AC Motor Using Fuzzy Controller for a Brewery Industry}

This objective required that a SIMULINK model be designed for the AC motor under operational condition for increased production output imbibing the already fuzzy controller. The designed Simulink model is shown in Figure 3. It was designed in such a way that after a real-time simulation, the production output would reflect an increase on the conventional production output.

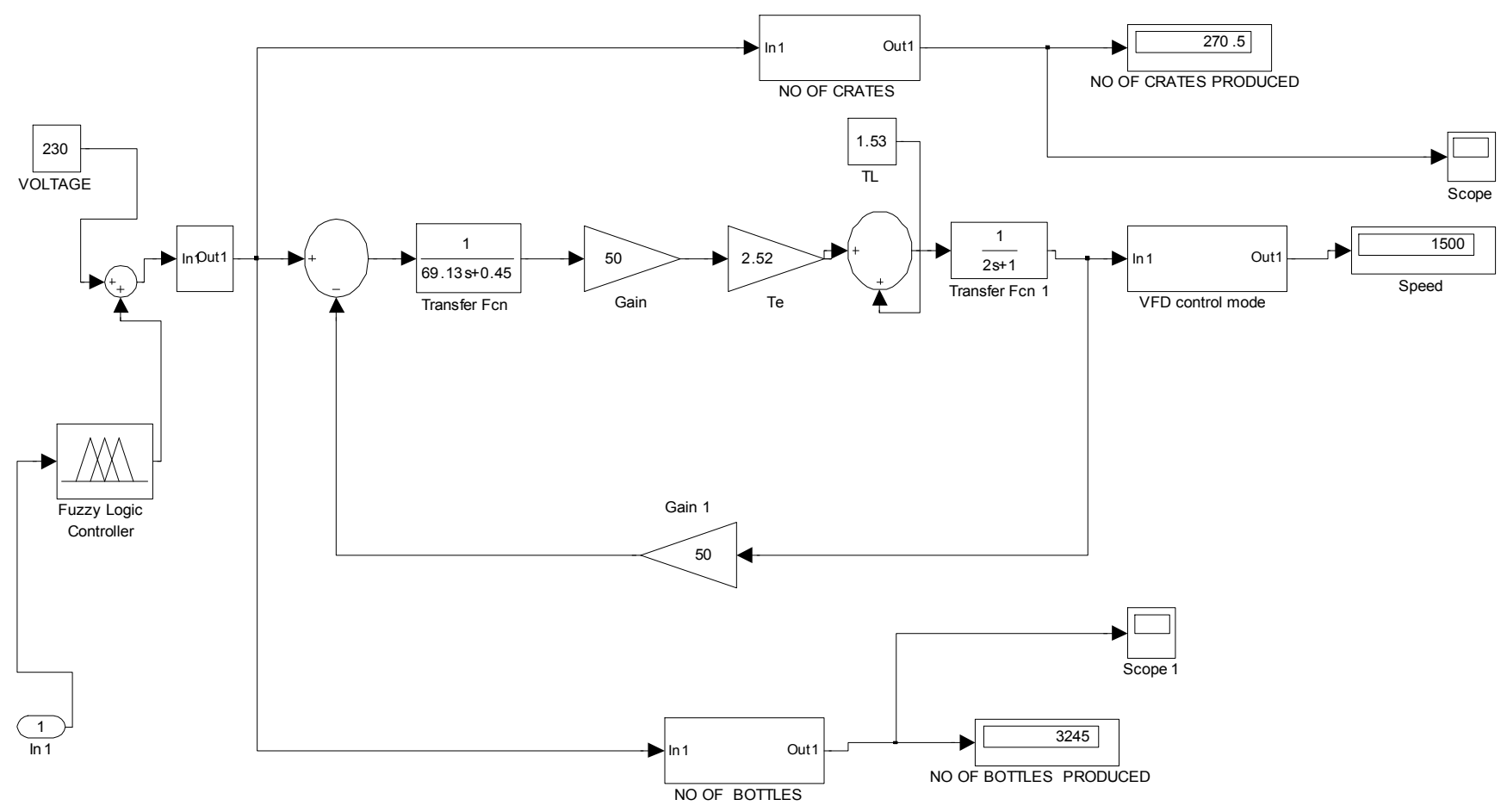

Figure 3. Simulink model of AC Motor with fuzzy controller for increased production output.

In this objective, it was required to validate and justify the work done in this research comparing conventional production output and fuzzy controller production output. The result obtained is as shown in figure 4.

\section{Results and Discussion}

Figure 1 Shows the block diagram of an AC motor Fuzzy controller Rule Base for AC motor stable and improved production output

Figure 2 Fuzzy controller Rule Base for AC motor stable and improved production output

The rule base module generated and shown in Figure 2 comprises a set of IF... THEN rules meant to guide the production principles and sequence using the $\mathrm{AC}$ induction motor as modeled using fuzzy controller. Table 3 shows a tabulated outline of this rule base. Figure 3. Depict a
Simulink model of AC Motor with fuzzy controller for increased production output. Unlike the usual methods of starting three phase induction motors, with voltage drops using direct on-line starting; the introduction of a controller like the Fuzzy controller does improve the efficiency of the machine performance.

In this objective, it was required to validate and justify the work done in this research by comparing conventional production output and fuzzy controller production output. The result obtained is shown in figure 4. It is clearly seen that the graph of conventional and fuzzy controller number of bottles of beer produced in brewery have a difference in terms of production output. In figure 4 the highest conventional quantity of bottles of beer produced was 3240 while that of fuzzy controller was 3245 at a stable time of 4 through 10 seconds. Table 4 is the Comparison of conventional and fuzzy controller number 
of bottles of beer produced in brewery as reflected in the

graph of Figure 4.

Table 4. Comparison of conventional and fuzzy controller number of bottles of beer produced in brewery.

\begin{tabular}{lll}
\hline Time (s) & $\begin{array}{l}\text { Conventional quantity of bottles of beer produced in brewery } \\
\text { (bottles) }\end{array}$ & $\begin{array}{l}\text { Fuzzy controller quantity of bottles of beer produced in } \\
\text { brewery (bottles) }\end{array}$ \\
\hline 0 & 0 & 0 \\
1 & 1980 & 2000 \\
2 & 2700 & 2800 \\
3 & 3050 & 3100 \\
4 & 3240 & 3245 \\
10 & 3240 & 3245 \\
\hline
\end{tabular}

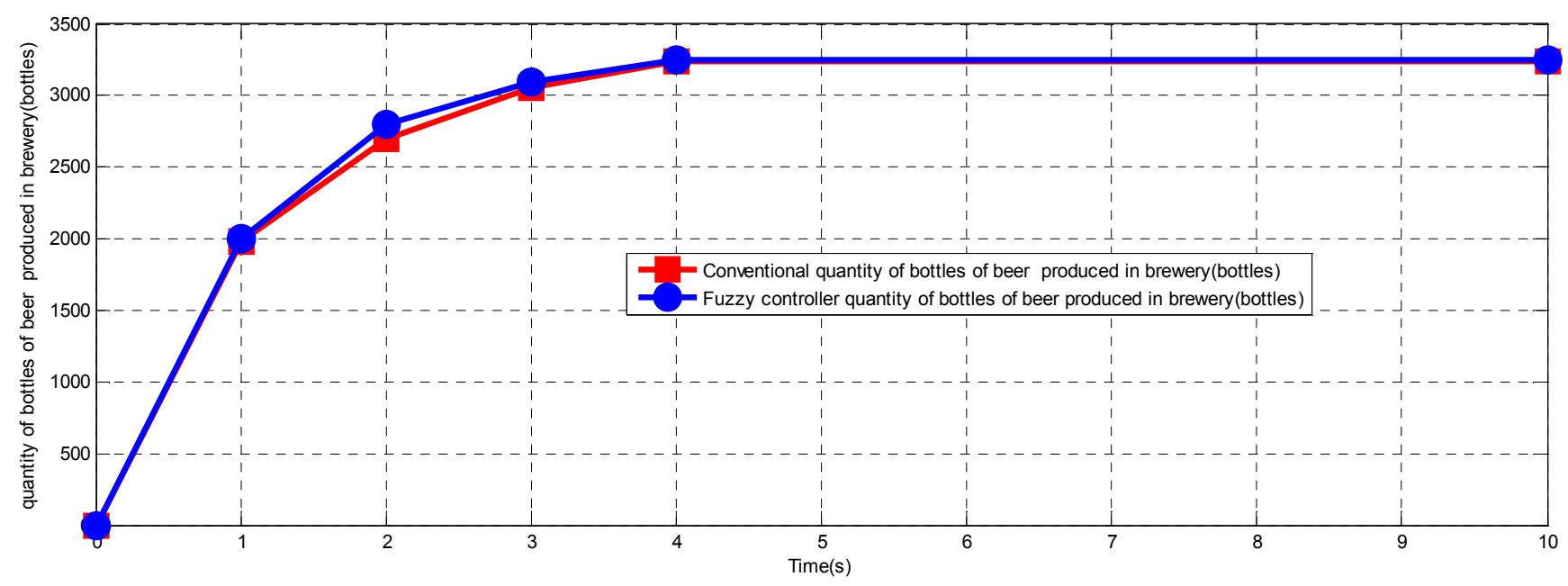

Figure 4. Graph of conventional and fuzzy controller number of bottles of beer produced in brewery.

\section{Conclusion}

The low production capacity experienced in our brewery industry is as a result of not imbibing intelligence in its production mechanism. To enhance the production mechanism in brewery industry, there should be an introduction of modeling of alternating current (a.c) motor performance for increased production output using fuzzy logic controller. It is done in this manner, characterizing and modeling a conventional AC motor so as to establish its operational features while working on variable frequency drive (VFD) control model with known production output, designing a rule base for the use of fuzzy controller for a stable and improved production output of $\mathrm{AC}$ motor and designing SIMULINK model for the performance of $\mathrm{AC}$ motor under operational condition for an increased output using fuzzy controller for a brewery industry. The results obtained are the highest conventional quantity of bottles of beer produced was 3240 while that of fuzzy controller was 3245 at a stable time of 4 through 10 seconds. With these results obtained, it shows there is an improvement in the production capacity when fuzzy controller is incorporated in the system.

\section{Acknowledgements}

Appreciation goes to the Faculty of Engineering, Enugu State University of Science and Technology for the use of resource materials necessary for the completion of this research work. This work is assisted by Ngatek Global Services Limited, a private company based in Cross River State, Nigeria whose corporate objective is to support and provide funds for research works.

\section{References}

[1] Adrienn Dineva 1 and Amir Mosavi (2019). Review of Soft Computing Models in Design and Control of Rotating Electrical Machine. Energies 2019, 12, 1049; doi: 10.3390/en12061049.

[2] Kouki Matsuse and Daiki Matsuhashi (2017): New Technical Trends on Adjustable Speed AC Motor Drives; Chinese Journal of Electrical Engineering, Vol. 3, No. 1, June 2017.

[3] M H. Mohammadi, R. C. P. and Silva, D. A Lowther,. (2018).'Incorporating Control Strategies Into the Optimization of Synchronous AC Machines: A comparison of Methodologies", IEEE Transaction on magnetics, vol. 54, no. 3.

[4] K. B. Ravindrakumar, K. Karthick and D. Sivanandakumar (2019). Fuzzy Based Approach for Direct Torque Control Of Three Phase Induction Motor. International Journal of Scientific \& Technology Research Volume 8, Issue 10.

[5] Maria Drakaki, Yannis L. Karnavas, Athanasios D. Karlis, Ioannis D. Chasiotis and Panagiotis Tzionas (2019): Study on Fault Diagnosis of Broken Rotor Bars in Squirrel Cage Induction Motors: A Multi-Agent System Approach Using Intelligent Classifiers; IET Electric Power Applications. 
[6] Uma Sabareesh, V \& Karthick, K 2019, Solar PV based Permanent Magnet Synchronous Motor Drive for Water Pumping Application', International Journal of Innovative Technology and Exploring Engineering (IJITEE), Blue Eyes Intelligence Engineering \& Sciences Publication, Vol. 8, No. 9, pp. 837-843.

[7] S. M. Tripathi and R. Vaish,(2019). "Taxonomic research survey on vector controlled induction motor drives," in IET Power Electronics, vol. 12, no. 7, pp. 1603-1615, 196.

[8] M. R. Barusu, U. Sethurajan and M. Deivasigamani, (2019). "Noninvasive method for rotor bar fault diagnosis in threephase squirrel cage induction motor with advanced signal processing technique," in The Journal of Engineering, vol. 2019, no. 17, pp. 4415-4419, 62019.

[9] N. B. b. Ahamad, C. Su, X. Zhaoxia, J. C. (2019). "Energy Harvesting From Harbor Cranes with Flywheel Energy Storage Systems," in IEEE Transactions on Industry Applications, vol. 55, no. 4, pp. 3354-3364.

[10] M. K. Metwaly, H. Z. Azazi, and S. A. Deraz,(2019) "Power Factor Correction of Three-Phase PWM AC Chopper Fed Induction Motor Drive System Using HBCC Technique," in IEEE Access, vol. 7, pp. 43438-43452.

[11] F. Khammar and N. E. Debbache (2016): Application of Artificial Intelligence Techniques for the Control of the Asynchronous Machine; Journal of Electrical and Computer Engineering Volume 2016, Article ID 8052027, 11 pages.
[12] Munira Batool and Aftab Ahmad (2013): Mathematical Modeling and Speed Torque Analysis of Three Phase Squirrel Cage Induction Motor Using MATLAB Simulink for Electrical Machines Laboratory; International Electrical Engineering Journal (IEEJ) Vol. 4 (2013) No. 1, pp. 880-889.

[13] Jithin J, K R Devika, Jasim Ali M and Krishnenedhu Murali (2019): Speed and Torque Control of 3 Phase Induction Motors using Periferal Interface Controller; International Journal of Research Studies in Electrical and Electronics Engineering (IJRSEEE) Volume 5, Issue 3, 2019, PP 1-4.

[14] Jinjie Huang, Shiyong Li, Chuntao Man. (2003). A TS type of fuzzy controller based on process of input output data", Proc. of 42nd IEEE Conf. on Decision \& Control (CDC'03), Hawai, USA, pp. 4729-4734.

[15] Mouloud Azzedine Denai, Sid Ahmed Atti. (2002). "Fuzzy and Neural Control of an Induction Motor", Proc. Int. J. Appl. Math. Comput. Sci., Vol. 12, No. 2, pp. 221-233.

[16] H Hartono and Sudjoko, R. I (2019) Journal of Physics Conference. Series. 1381012053.

[17] Ngang N. B. (2020). Hydro power Generator speed control using Fuzzy software Tool. International Journal of Emerging Trends in Engineering and Development (IJETED) Vol. 3, No. 10, DOI: https://dx.doi.org/10.26808/rs.ed.i10v3.02. 